\title{
Indoor particle counts during Asian dust events under everyday conditions at an apartment in Japan
}

\author{
Kumiko T. Kanatani $\cdot$ Motonori Okumura • \\ Susumu Tohno • Yuichi Adachi $\cdot$ Keiko Sato • \\ Takeo Nakayama
}

Received: 8 June 2013/Accepted: 21 July 2013/Published online: 10 August 2013

(C) The Japanese Society for Hygiene 2013

\begin{abstract}
Objective Asian dust storms originating from arid regions of Mongolia and China are a well-known springtime phenomenon throughout East Asia. Evidence is increasing for the adverse health effects caused by airborne desert dust inhalation. Given that people spend approximately $90 \%$ of their time indoors, indoor air quality is a significant concern. The present study aimed to examine the influence of outdoor particulate matter (PM) levels on indoor PM levels during Asian dust events under everyday conditions.

Methods We simultaneously monitored counts of particles larger than $0.3,0.5,1,2$, and $5 \mu \mathrm{m}$ using two directreading instruments (KC-01D1 airborne particle counter; Rion), one placed in an apartment room and another on the veranda, under everyday conditions before and during an Asian dust event. We also examined how indoor particle counts were affected by opening a window, crawling, and air purifier use.

Results An Asian dust event on 24 April 2012 caused 50and 20-fold increases in PM counts in outdoor and indoor
\end{abstract}

\footnotetext{
K. T. Kanatani $(\bowtie) \cdot$ T. Nakayama

Graduate School of Medicine, Kyoto University,

Yoshida-Konoe-cho, Sakyo, Kyoto 606, Japan

e-mail: kanatanik@mac.com

M. Okumura $\cdot$ S. Tohno

Graduate School of Energy Science, Kyoto University,

Yoshda-Honmachi, Sakyo, Kyoto 606-8501, Japan

Y. Adachi

Department of Pediatrics, Faculty of Medicine, University

of Toyama, Sugitani 2630, Toyama 930-0194, Japan

K. Sato

Department of Medicine, Kyoto University,

Yoshida-Konoe-cho, Sakyo, Kyoto 606, Japan
}

air, respectively. A window open for 10 min resulted in a rapid increase of indoor PM counts up to $70 \%$ of outside levels that did not return to baseline levels after $3 \mathrm{~h}$. An air purifier rapidly reduced PM counts for all particle sizes measured.

Conclusions It is important to account for occupant behavior, such as window-opening and air purifier use, when estimating residential exposure to particulate matter.

Keywords Indoor air · PM2.5 · PM10 - Dust storm . Asian dust

\section{Introduction}

Asian dust events are well-known spring phenomena in East Asia that originate from the deserts of Mongolia and China. Asian cities experience yellow air on several days in the spring when the dust is blowing. The dust includes quartz, an amorphous and crystalline silica known to cause respiratory disease in people with occupational exposure or high levels of exposure from living close to deserts [1-4] and inflammation in the lungs of rats in experimental studies [5-8]. Further, dust particles contain chemicals derived from air pollutants, such as sulfate $\left(\mathrm{SO}_{4}{ }^{2-}\right)$ and nitrate $\left(\mathrm{NO}_{3}{ }^{-}\right)$, as well as microbial agents, including bacteria, fungi, fungal spores, and viruses, that sometimes survive long-distance transportation [9-11]. The impact of airborne dust may be exacerbated by these potential allergens and pathogens.

Epidemiological studies also provide increasing evidence of adverse health effects from airborne desert dust inhalation. Hospitalization risk increases significantly for asthmatic children [12], as do emergency ambulance dispatches [13] after Asian dust events in Japan. Non-accidental mortality and cardiovascular mortality also increase significantly after 
Asian dust events in Taiwan [14]. A Korean study, where the influence of desert dust was not necessarily specifically investigated, also shows that particulate matter (PM) number as well as mass concentration are significantly associated with respiratory and cardiovascular disease-related mortality among the elderly [15].

Given that people spend approximately $90 \%$ of their time indoors [16], indoor air quality is a significant concern. In Japan, the season for Asian dust events coincides with one of the most comfortable periods of the year. Our preliminary investigation (unpublished data) revealed that approximately half of the pregnant women in Kyoto, Japan, opened windows every day during April 2012 (1794 respondents/2107 queried).

We investigated how indoor PM counts (larger than 0.3, $0.5,1,2$, and $5 \mu \mathrm{m}$, respectively) are influenced by various factors, including window/door openness, activity (crawling), and air purifier use, under everyday conditions in an apartment in Japan on days with Asian dust events.

\section{Methods}

\section{Monitoring situation}

We monitored PM counts in a room on the 10th floor of an apartment building in a residential area of Kyoto. There is a $100 \mathrm{~m}$ distance from the apartment building to the nearest two-way road. The building is a reinforced concrete structure built in 2001, 11 years before this study.

The apartment is a $4 \mathrm{LDK}$ with $86 \mathrm{~m}^{2}$ floor area, occupied by two adults and an 11-year-old girl. None of the occupants are at home during the daytime and all three are non-smokers. The floor is wooden and shoes are strictly prohibited in the rooms in accordance with Japanese culture. The monitored room of the apartment has a $22 \mathrm{~m}^{2}$ floor area and is shown in Fig. 1. The door in the monitored room was kept closed throughout the study period except when occupants went in or out, but there is a $0.8 \mathrm{~cm}$-wide space at the bottom of the door even when it is closed. An air purifier was constantly used in the living/dining room during the observational period $\left(2 \mathrm{~m}^{3} / \mathrm{min}\right.$ airflow) and was moved to the monitored room for the experiment.

The study period was composed of an observational period and an experimental period. An observational period was composed of a control period and an Asian dust period (Fig. 2). In the experimental periods, we performed experiments of opening windows $(20 \mathrm{~cm}, 10 \mathrm{~min})$ or airpurifier use to see how these factors affect the PM counts indoors. We also performed an experiment of crawling (a researcher, $160 \mathrm{~cm}$ height, crawled on the floor for $10 \mathrm{~min}$ ) to see if dust fallen on the floor affects the indoor air again because of activities.

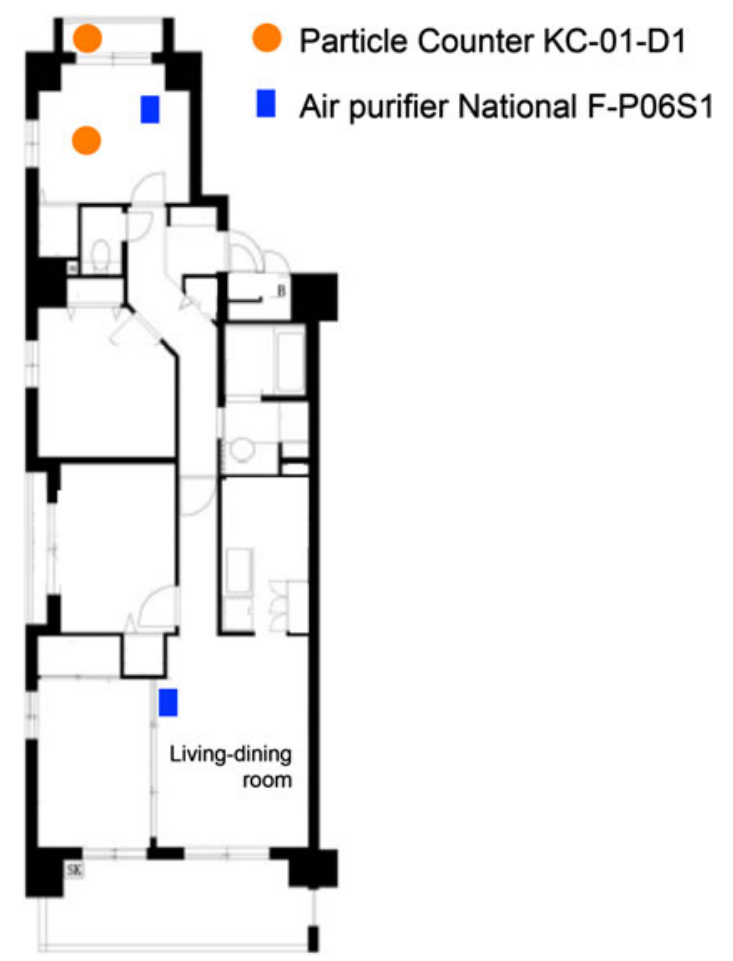

Fig. 1 Floor plan of the monitored apartment. Two particle counters (solid circles) were used. One was placed $20 \mathrm{~cm}$ above the floor in the monitored room and the other was placed $120 \mathrm{~cm}$ above the veranda floor. An air purifier (solid rectangle) was placed in the living-dining room during the observational period and moved to the monitored room for the experiment

\section{Monitoring equipment}

The direct-reading instrument used to measure particle size and count was a Rion KC-01-D1 airborne particle counter. The machine simultaneously counts particles larger than 0.3 , $0.5,1,2$, and $5 \mu \mathrm{m}$. We concurrently monitored the indoor PM counts $20 \mathrm{~cm}$ above the floor, and outdoor PM counts $120 \mathrm{~cm}$ above the veranda floor (Fig. 1). The flow rate was $0.5 \mathrm{~L} / \mathrm{min}$, and particle counts were measured every $2 \mathrm{~min}$.

Room variables recorded during the study period included the following: window (open/closed), room door (open/closed), air conditioner (on/off), ventilation system (on/off), cooking in the apartment (yes/no), and the number of persons present during the testing.

Information regarding desert dust concentration was provided by light detection and ranging (LIDAR) with a polarization analyzer in Osaka [17, 18], which distinguishes soil dust (non-spherical particles) from atmospheric pollutants (spherical particles) by measuring the extent of scattered reflected light $[19,20]$. We used the data for an altitude of $135 \mathrm{~m}$. Suspended particulate matter (SPM; PM7) was measured at an air quality monitoring station in Kyoto located approximately $5 \mathrm{~km}$ from the apartment building. 
Fig. 2 Local SPM

measurements during the control and Asian dust periods

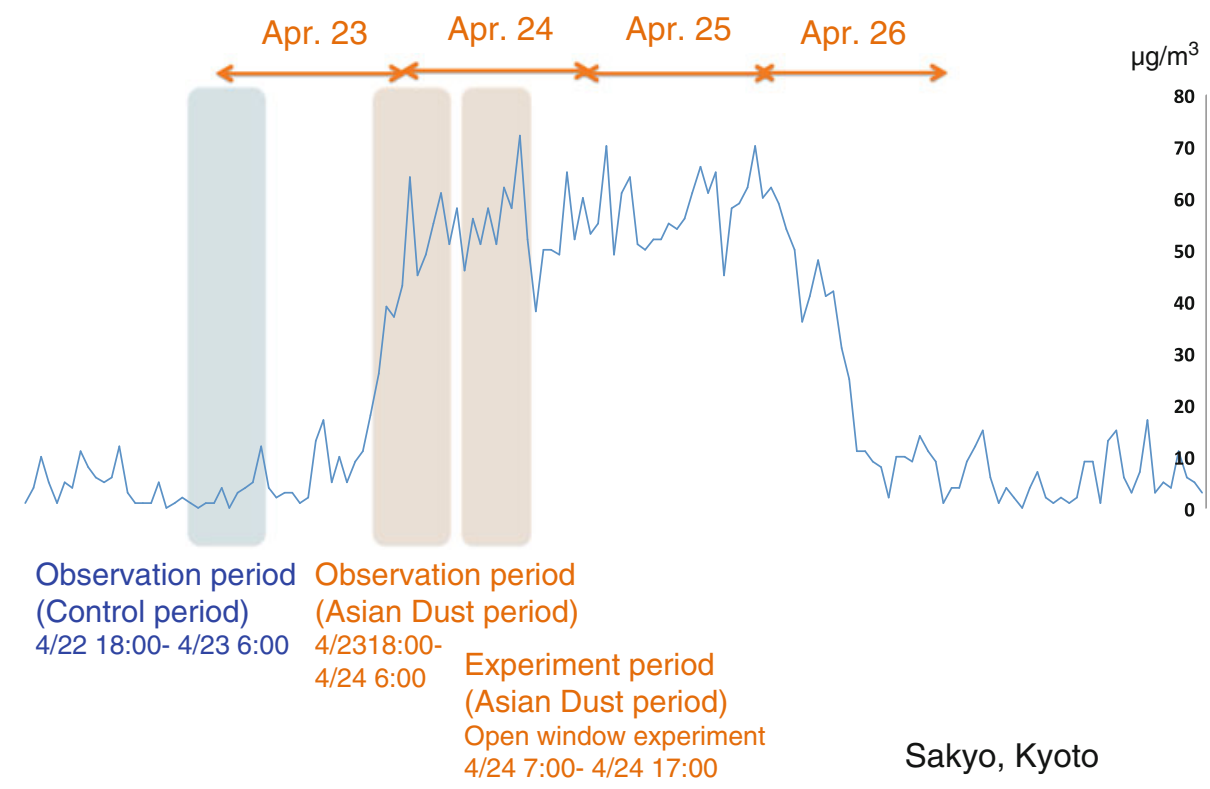

Apr. 22, 2012 12:00

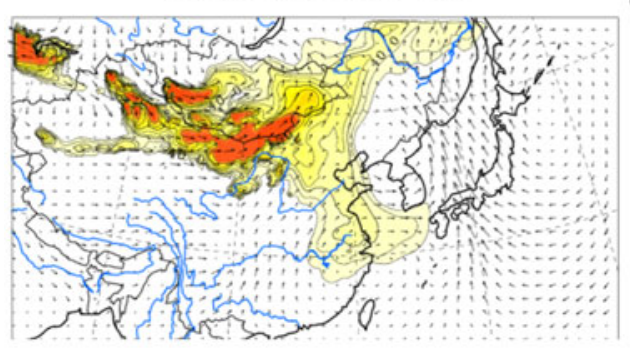

$\mu \mathrm{g} / \mathrm{m}^{3}$

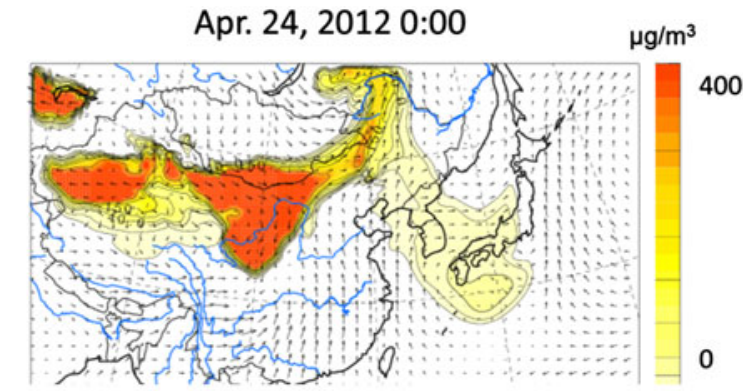

Apr. 23, 2012 0:00

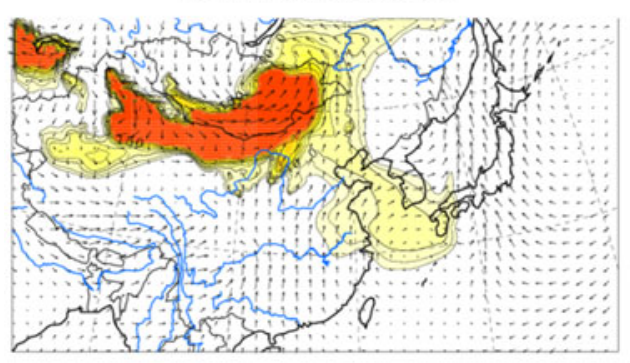

$\mu \mathrm{g} / \mathrm{m}^{3}$

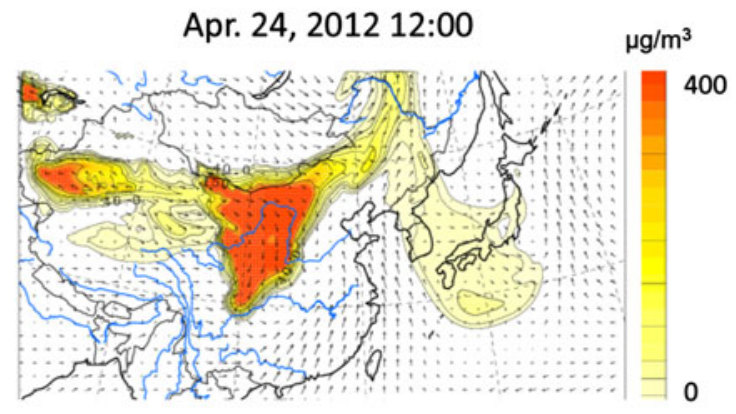

Apr. 23, 2012 12:00

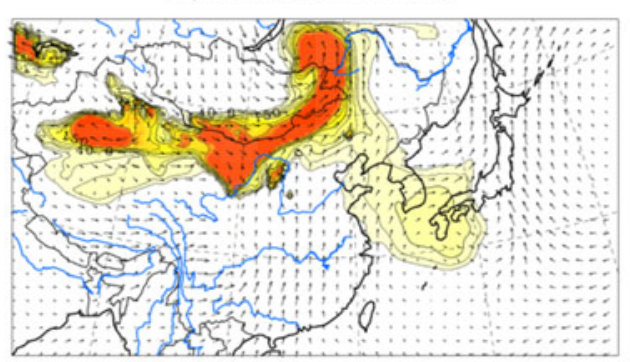

$\mu \mathrm{g} / \mathrm{m}^{3}$

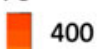

400

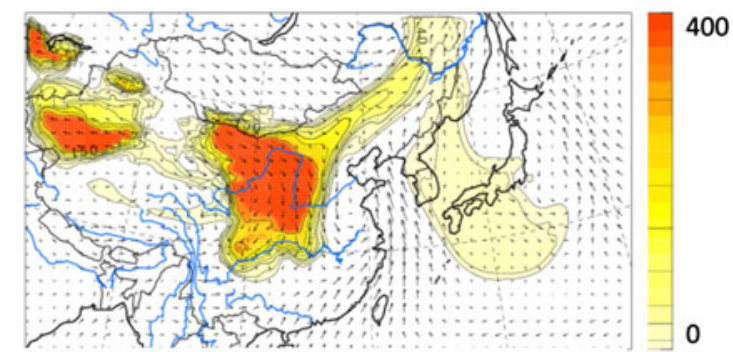

Fig. 3 Asian dust distribution prediction by the Chemical Weather Forecast System [17]. The Asian dust clouds were predicted to arrive in Kyoto at noon on 23 April 2012 


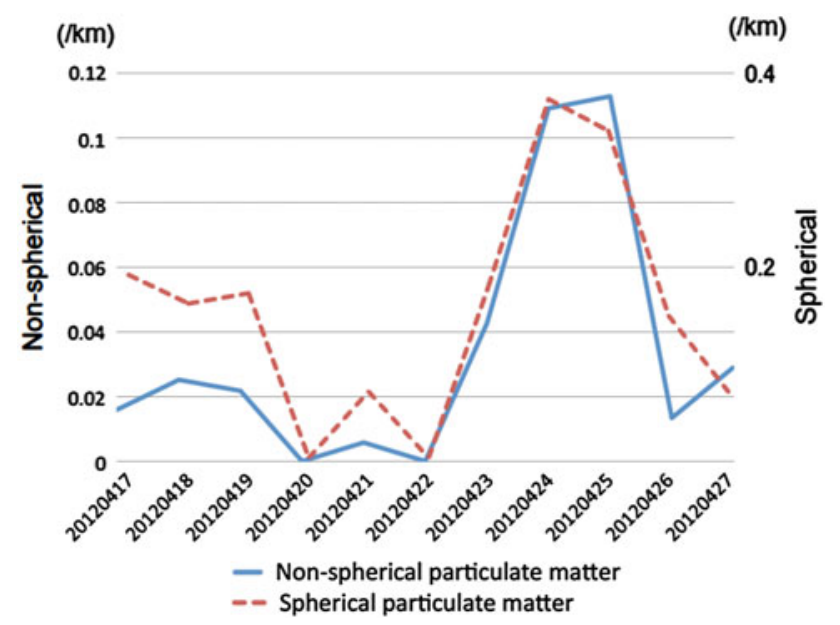

Fig. 4 Estimation of non-spherical and spherical particle concentrations by light detection and ranging (LIDAR) [21]

\section{Results}

Forecast and station data during the study period (22-25 April 2012)

The Chemical Weather Forecast System (CFORS) predicted the arrival of an Asian dust cloud in Kyoto at noon on 23 April (Fig. 3) [21, 22], and LIDAR in Osaka measured high concentrations of soil dust during the same period (Fig. 4) [17, 18].

SPM measured by the Atmospheric Environmental Regional Observation System at a local site in Kyoto, $5 \mathrm{~km}$ from the apartment, increased from the afternoon of 23 April until the morning of 26 April (Fig. 2).

Notably, CFORS predicted increased sulfate in the air during the same period (Fig. 5) [21], and an increase in the spherical particulate matter was observed by LIDAR
Apr. 22, 2012 12:00

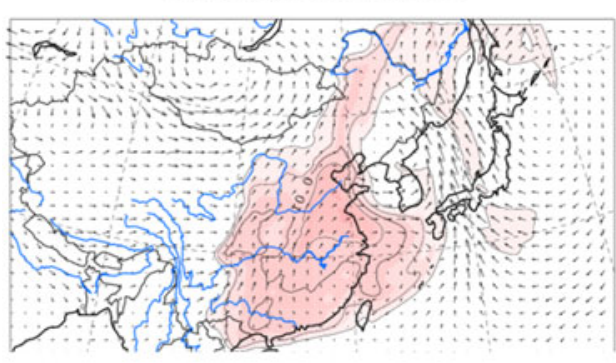

Apr. 23, 2012 0:00

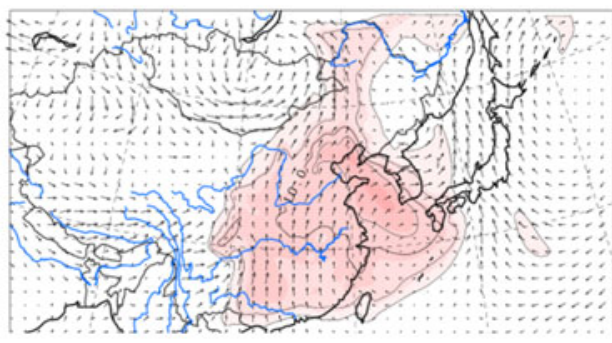

Apr. 23, 2012 12:00

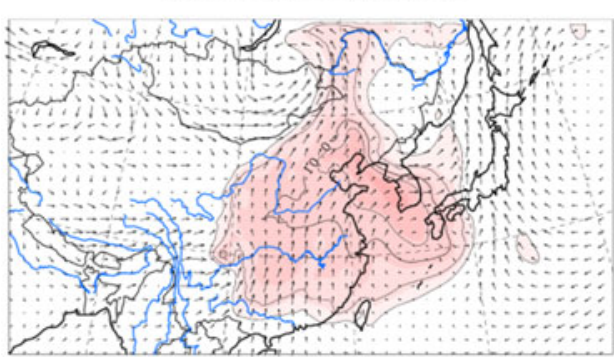

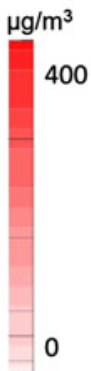

$\mu \mathrm{g} / \mathrm{m}^{3}$

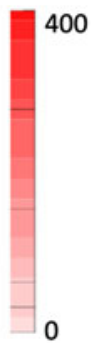

$\mu \mathrm{g} / \mathrm{m}^{3}$

400

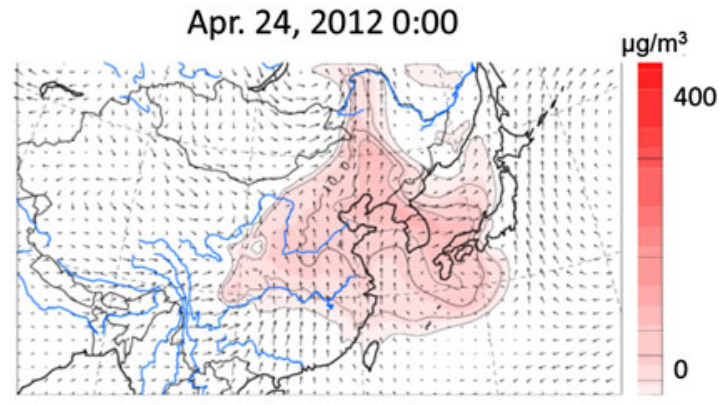

Apr. 24, 2012 12:00

$\mu \mathrm{g} / \mathrm{m}^{3}$

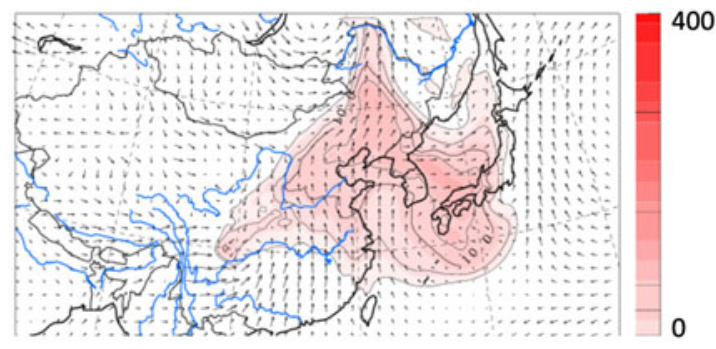

Apr. 25, 2012 0:00

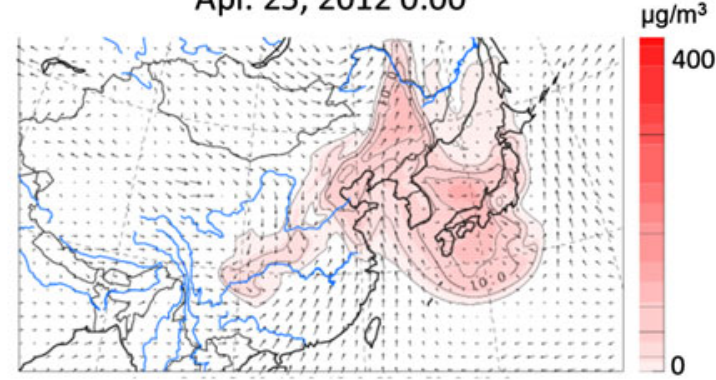

Fig. 5 Sulfate distribution prediction by the Chemical Weather Forecast System [17] 
Particle counts of $>5 \mu \mathrm{m}$
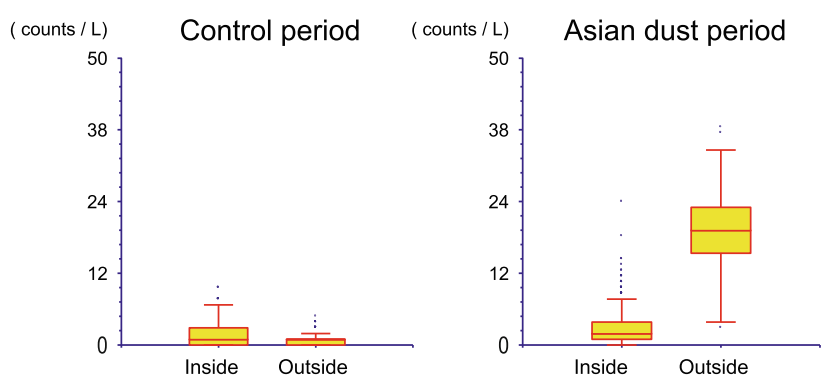

Particle counts of $>2 \mu \mathrm{m}$
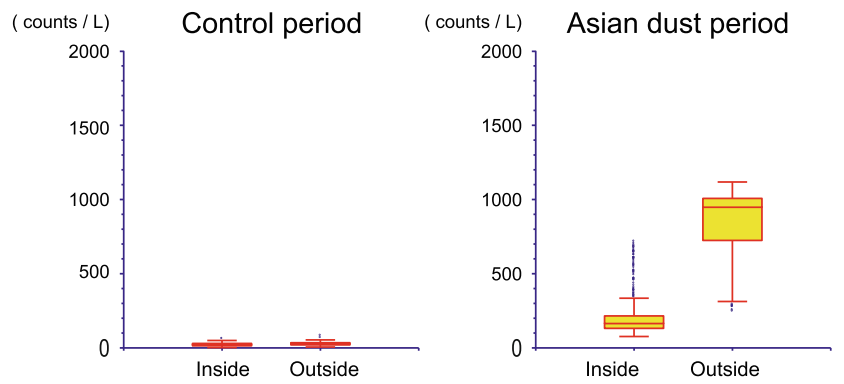

Particle counts of $>1 \mu \mathrm{m}$
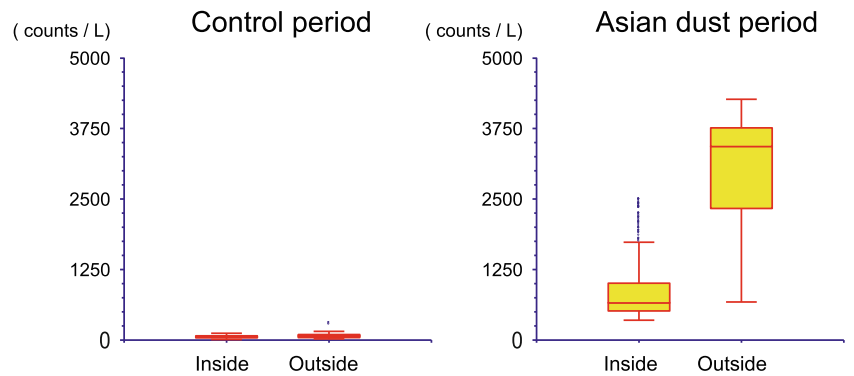

Particle counts of $>0.5 \mu \mathrm{m}$
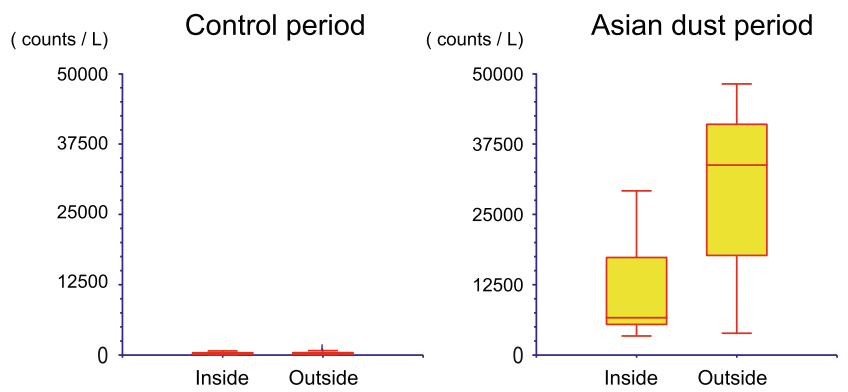

Particle counts of $>0.3 \mu \mathrm{m}$
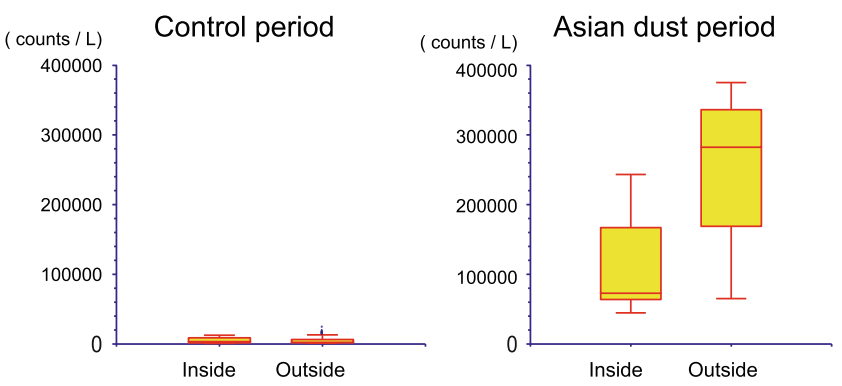

Fig. 6 Comparison of particle counts/L inside and outside during control (left) and Asian dust (right) periods

during this Asian dust event (Fig. 4) [17], which was considered to be trans-boundary air pollution flying simultaneously with Asian dust.

Indoor and outdoor PM counts (/L)

before and during dust storms

Figure 6 shows indoor and outdoor air PM counts (/L) before and during a dust storm with closed windows, without airconditioner use in the monitored room, and without cooking throughout the study period. A room door was opened twice during each period and the apartment door was opened twice for short periods of time (several seconds) during each period. Before the dust storm, the PM (particles $>0.3 \mu \mathrm{m}$ ) counts were very low both indoors and outdoors (indoors: mean 5186/L, range 921-12 670/L; outdoors: mean 4779/L, range 1154-23 637/L). During the dust storm, the indoor PM (particles $>0.3 \mu \mathrm{m}$ ) counts increased approximately 20-fold, while the outdoor PM counts increased approximately 50-fold (indoors: mean 115 340/L, range 44 737-243 399/L; outdoors: mean 250 867/L, range 65 152-375 367/L; Fig. 6). Indoors, smaller PM levels seemed to be more influenced by outdoor PM levels than larger PM levels (Fig. 6).

Factors that affect indoor PM counts

Figure 7 shows the time course of PM counts through the experiments. Opening a window $(20 \mathrm{~cm})$ for $10 \mathrm{~min}$ resulted in a rapid increase in PM counts up to $70 \%$ of outdoor levels. Smaller PM sizes remained longer in room air, as high as $50 \%$ of outdoor levels for PM greater than 0.5 and $0.3 \mu \mathrm{m}$ even after 3 h. A researcher's crawling caused an increase in counts of PM larger than $1 \mu \mathrm{m}$. An air purifier (non-HEPA filter, $3 \mathrm{~m}^{3} / \mathrm{min}$ airflow) reduced PM counts for all sizes in $30 \mathrm{~min}$. With the air purifier on, window opening $(20 \mathrm{~cm})$ for 10 min still caused elevation of PM counts up to $50 \%$ of outdoor levels, but counts for all sizes rapidly returned to baseline levels after closing the window. 

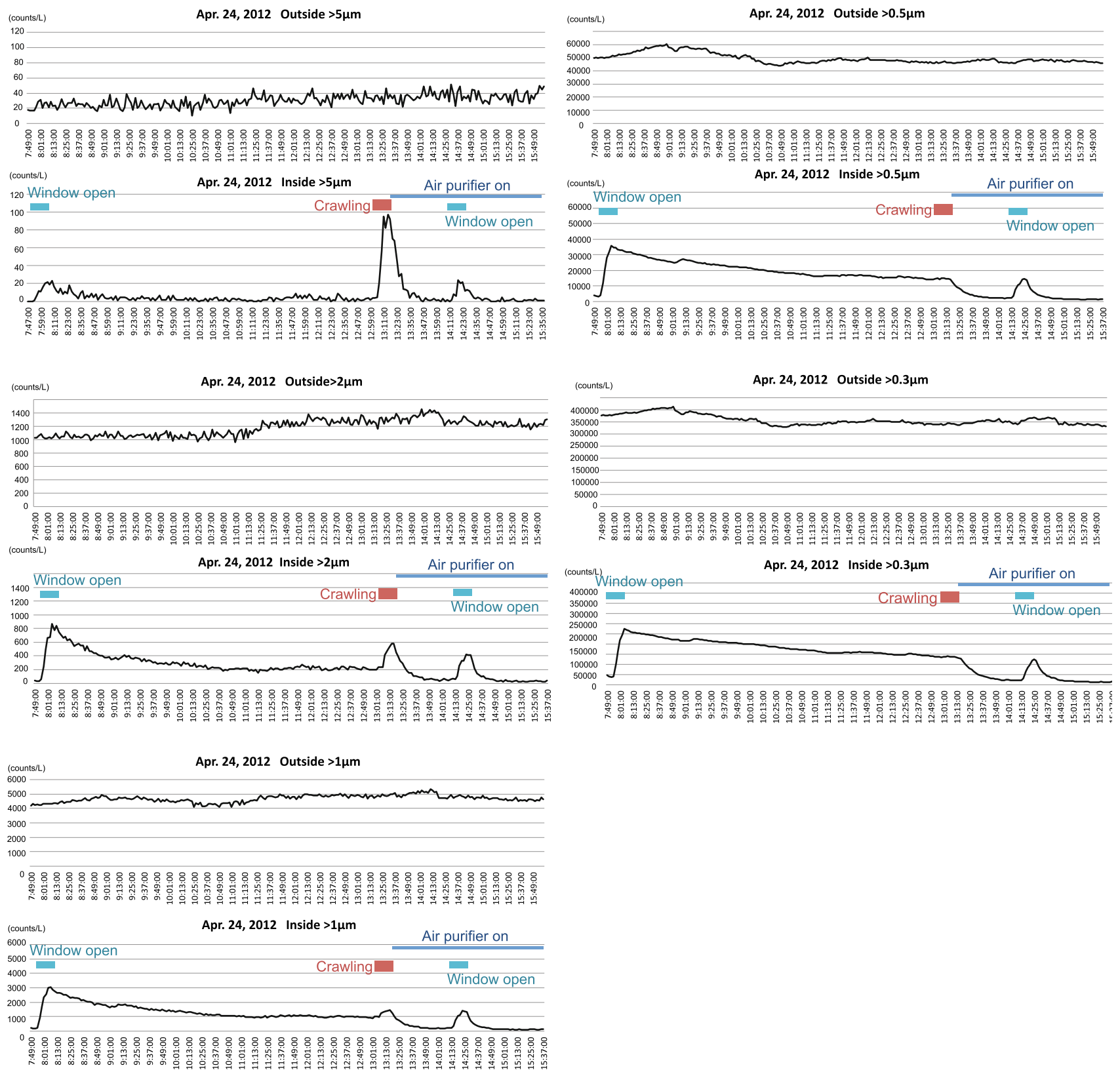

Fig. 7 PM counts/L in outdoor (upper) and indoor (lower) air under various conditions

\section{Discussion}

This study measured indoor and outdoor particle counts during an Asian dust event under everyday conditions. An Asian dust event on 24 April 2012 caused a 50-fold increase in PM counts outdoors and a 20-fold increase indoors in an apartment room in Japan. As far as we know, there is one report regarding PM changes in indoor air during Asian dust events at an office building in Taipei [23]. This report showed that indoor PM2.5 and PM10 increased threefold during the dust storm while outdoor PM2.5 and PM10 increased 1.7-fold. The ventilation systems in this high-rise building utilize air from outside, and the authors concluded that this was likely the primary reason that air particle concentrations inside the building were significantly affected by outside air pollutants during dust storms. The ventilation system in our apartment was used once for $20 \mathrm{~min}, 2 \mathrm{~h}$ before observation began. We speculate that, in addition to this ventilation, the occupants opening doors and their movements into and out of the rooms were the main routes for PMs entering the monitored room.

The PM increase observed in this study was larger than in the Taipei study. One explanation for this is that 
the baseline count was very low in our study (mean SPM during the control period was $1.7 \mu \mathrm{g} / \mathrm{m}^{3}$, range $0-5 \mu \mathrm{g} / \mathrm{m}^{3}$ ) compared to the control period in Taipei (PM2.5 and PM10 were 45 and $70 \mu \mathrm{g} / \mathrm{m}^{3}$, respectively). Second, in this study, air pollution other than desert dust was also observed during the Asian dust period; CFORS predicted sulfate aerosol arrival in our Asian dust period and LIDAR observed spherical as well as non-spherical particulate matter during this time period. Accordingly, the observed PM count increase is considered to be a mixture of desert dust and other air pollution. Finally, this study and the Taipei study may have also differed in the original scale of the Asian dust storms observed.

An open window $(20 \mathrm{~cm})$ for $10 \mathrm{~min}$ resulted in a rapid increase of indoor PM counts up to $70 \%$ of outside levels, which was maintained for $3 \mathrm{~h}$ after closing the window. An air purifier rapidly reduced the PM counts for all particle sizes larger than $0.3 \mu \mathrm{m}$.

Previous reports have often noted that air change rates in occupied houses are highest when weather conditions are mild, and several investigators have speculated that this is due to increased window-opening behavior under mild conditions. Iwashita and Akasaka measured ventilation rates using gas tracers and questionnaire surveys assessing indoor environment and residents' behavior, and concluded that $87 \%$ of the total air change rate was due to occupant behavior [24]. United States researchers quantitatively confirmed that having a single window open can increase air change rates [25].

This study's PM observations indoors and outdoors during an Asian dust event are consistent with the previous reports above and suggest the importance of accounting for occupant behavior, such as window-opening and air purifier use, when estimating residential exposure to particulate matter.

In conclusion, Asian Dust arrival caused a 50-fold increase in PM counts outdoors and a 20-fold increase indoors under everyday conditions on 24 April 2012, in Kyoto, Japan.

A window open for $10 \mathrm{~min}$ resulted in a rapid increase of indoor PM counts up to $70 \%$ of outside levels that was maintained for $3 \mathrm{~h}$. An air purifier rapidly reduced PM counts for all particle sizes larger than $0.3 \mu \mathrm{m}$.

The results suggest it is important to account for occupant behavior, such as window-opening and air purifier use, when estimating residential exposure to particulate matter.

Acknowledgments We thank Dr. Nobuo Sugimoto for providing LIDAR data, the Kyoto City Environmental Protection Guidance Division for SPM data, Dr. Itsushi Uno for CFORS images, and Mr. Tadashi Hioki for fruitful discussion. This research was supported by the Environment Research and Technology Development Fund (C1152) of the Ministry of the Environment, Japan.
Conflict of interest The authors declare no conflict of interest.

\section{References}

1. Griffin DW. Atmospheric movement of microorganisms in clouds of desert dust and implications for human health. Clin Microbiol Rev. 2007;20:459-77.

2. Valiante DJ, Schill DP, Rosenman KD, Socie E. Highway repair: a new silicosis threat. Am J Public Health. 2004;94:876-80.

3. Eagan TM, Gulsvik A, Eide GE, Bakke PS. Occupational airborne exposure and the incidence of respiratory symptoms and asthma. Am J Respir Crit Care Med. 2002;166:933-8.

4. Kassimi FA, Majed SA, Hajjaj MS. Silicosis in a Himalayan village population: role of environmental dust. Thorax. 1991;46: $861-2$.

5. Ichinose T, Yoshida S, Sadakane K, Takano H, Yanagisawa R, Inoue $\mathrm{K}$, et al. Effects of Asian sand dust, Arizona sand dust, amorphous silica and aluminum oxide on allergic inflammation in the murine lung. Inhal Toxicol. 2008;20:685-94.

6. He M, Ichinose T, Yoshida S, Yamamoto S, Inoue K, Takano H, et al. Asian sand dust enhances murine lung inflammation caused by Klebsiella pneumoniae. Tox App Pharm. 2012;258:237-47.

7. Murphy SA, Be'rube'a KA, Pooleya FD, Richards RJ. The response of lung epithelium to well characterised fine particles. Life Sci. 1988;62:1789-99.

8. Mancino D, Vuotto ML, Minucci M. Effects of a crystalline silica on antibody production to T-dependent and T-independent antigens in Balb/c mice. Int Arch Allergy Appl Immunol. 1984;73:10-3.

9. Chen PS, Tsai FT, Lin CK, Yang CY, Chan CC, Young CY, et al. Ambient influenza and avian influenza virus during dust storm days and background days. Environ Health Perspect. 2010;118: 1211-6.

10. Kobayashi F, Kodanikuchi K, Kakikawa M, Maki T, Yamada M, Tobo Y, et al. Direct samplings, separated culture, and identifications of Kosa bioaerosols over Noto Peninsula, Suzu City (Japanese). Earozoru Kenkyu. 2010;25:23-8.

11. Maki T, Susuki S, Kobayashi F, Kakikawa M, Tobo Y, Yamada $\mathrm{M}$, et al. Phylogenetic analysis of atmospheric halotolerant bacterial communities at high altitude in an Asian dust (KOSA) arrival region, Suzu City. Sci Total Environ. 2010;408:4556-62.

12. Kanatani KT, Ito I, Al-Delaimy WK, Adachi Y, Mathews WC, Ramsdell JW, et al. Desert dust exposure is associated with increased risk of asthma hospitalization in children. Am J Respir Crit Care Med. 2010;182:1475-81.

13. Ueda K, Shimizu A, Nitta H, Inoue K. Long-range transported Asian Dust and emergency ambulance dispatches. Inhal Toxicol. 2012;12:858-67.

14. Chan $\mathrm{CC}, \mathrm{Ng} \mathrm{HC}$. A case-crossover analysis of Asian dust storms and mortality in the downwind areas using 14-year data in Taipei. Sci Total Environ. 2011;410-411:47-52.

15. Cho YS, Lee JT, Jung CH, Kim YS. Relationship between particulate matter measured by optical particle counter and mortality in Seoul, Korea, during 2001. J Environ Health. 2008;71(2): $37-43$.

16. Lunden MM, Thatcher TL, Hering SV, Brown NJ. Use of timeand chemically resolved particulate data to characterize the infiltration of outdoor PM2.5 into a residence in the San Joaquin Valley. Eiviron. Sci Technol. 2003;37:4724-32.

17. http://soramame.taiki.go.jp/dss/kosa/en/index.html.

18. Sugimoto N, Lee $\mathrm{CH}$. Characteristics of dust aerosols inferred from lidar depolarization measurements at two wavelengths. Appl Opt. 2006;45:7468-74.

19. Shimizu A, Sugimoto N, Matsui I, Arao K, Uno I, Murayama T, Kagawa N, Aoki K, Uchiyama A, Yamazaki A. Continuous 
observations of Asian dust and other aerosols by polarization lidar in China and Japan during ACE-Asia. J Geophys Res. 2004;109:D19S17. doi:10.1029/2002JD003253.

20. Sugimoto N, Uno I, Nishikawa M, Shimizu A, Matsui I, Dong X, Chen Y, Quan H. Record heavy Asian dust in Beijing in 2002: observations and model analysis of recent events. Geophys Res Lett. 2002;30(12):1640. doi:10.1029/2002GL016349 2003.

21. http://www-cfors.nies.go.jp/ cfors/.

22. Uno I, Carmichael GR, Streets DG, Tang Y, Yienger JJ, Satake S, et al. Regional chemical weather forecasting system CFORS: model descriptions and analysis of surface observations at
Japanese island stations during the ACE-Asia experiment. J Geophys Res. 2003;108(D23):8668.

23. Kuo H-W, Shen H-Y. Indoor and outdoor PM 2.5 and PM 10 concentrations in the air during a dust storm. Build Environ. 2010;45:610-4.

24. Iwashita G, Akasaka H. The effects of human behavior on natural ventilation rate and indoor air environment in summer - a field study in southern Japan. Energy Build. 1997;25:195-205.

25. Howard-Reed C, Wallace LA, Ott WR. The effect of opening windows on air change rates in two homes. $\mathrm{J}$ Air Waste Manage Assoc. 2002;52:147-59. 